\title{
Gestão de Espaços Públicos: o Caso da Praça Memorial 17 de Julho
}

Management of Public Spaces: The Case of Memorial Square July 17

Gestión de espacios públicos: el caso de la Plaza Memorial 17 de Julio

\author{
Neiva Viriato Viana \\ Mestranda GeAS, UNINOVE, Brasil \\ neiva.menezes41@gmail.com
}

Keila Karoline Magalhães Marques

Graduanda, UNINOVE, Brasil

keilamagalhaesmarques@gmail.com

Ana Paula do Nascimento Lamano-Ferreira

Professora Doutora, UNINOVE, Brasil. ana_paula@uni9.pro.br 



\section{INTRODUÇÃO}

O artigo 182 da Constituição da República Federativa do Brasil de 1988, determina que o Poder Público Municipal, por meio da política de desenvolvimento urbano, deve garantir as funções sociais da cidade e garantir o bem-estar de seus habitantes. De acordo com o estudo de Dorigo e Lamano-Ferreira (2015) o contato com a natureza pode oferecer benefícios imensuráveis para o ser humano principalmente em grandes centros urbanos, em que este contato muitas vezes é limitado. Na Dinamarca grande parte da população, visita espaços verdes pelo menos uma vez na semana, com intuito de aproveitar o ar fresco (SCHIPPERIJNA et al., 2010). Dessa forma, áreas como parques e praças auxiliam na melhoria da qualidade de vida da população de diversas formas.

Loboda e De Angelis (2005) complementam que espaços públicos com vegetação, influenciam de forma positiva o psicológico e emocional do ser humano, proporcionando sensações de relaxamento em meio aos grandes edifícios das metrópoles. Além disso, áreas verdes atenuam a poluição sonora e buscam equilibrar o clima, propiciando conforto térmico a frequentadores. Além de serem espaços de lazer, onde o ser humano pode expressar suas atividades.

A gestão de áreas verdes no município de São Paulo não é realizada de forma integrada. Os parques são administrados pela Secretaria Municipal do Verde e do Meio Ambiente, enquanto que as praças são de responsabilidade das Prefeituras Regionais. Com relação às praças, o gestor de cada uma das 31 Prefeituras Regionais, demonstra satisfação na autonomia para tomada de decisões referentes às áreas sob seus cuidados. No entanto, os recursos são limitados, os quais também são destinados a outros fins. Ademais, muitos deles afirmam que a escassez de dados de praças nos registros municipais, juntamente com a falta da conscientização da população e a falta de mão de obra das prefeituras regionais traz consequências diretas na manutenção e conservação das praças (BENCHIMOL; LAMANOFERREIRA, 2015).

Em 17 de julho de 2007, o maior acidente aéreo da América Latina e o maior acidente aéreo no mundo com uma aeronave Airbus A320, teve lugar no Aeroporto de Congonhas, na zona Sul da capital paulista. A aeronave Airbus A320, prefixo PR-MBK, da TAM Linhas Aéreas, hoje nomeada de LATAM Airlines Group, estava realizando o Voo JJ 3054 - Porto Alegre (RS) a São Paulo (SP).

A aeronave tendo decolado do Aeroporto Internacional Salgado Filho, em Porto Alegre, por volta das $17 \mathrm{~h} 19 \mathrm{~m}$, com destino ao Aeroporto de Congonhas, onde, após tocar a pista, perto das $18 \mathrm{~h} 45 \mathrm{~m}$, não conseguiu frenar, atravessando a Avenida Washington Luís, chocando-se com um prédio da própria TAM - TAM Express, no ramo de cargas da empresa aérea - em que ocasionou a morte de todas as pessoas a bordo, sendo seis tripulantes ativos e 181 passageiros.

Em decorrência deste acidente, pereceram ainda 12 pessoas que estavam fora da aeronave, seriam eles, funcionários e clientes da TAM e um taxista que estava no posto de gasolina ao lado. Totalizando 199 pessoas que perderam suas vidas (CENIPA, 2009).

A empresa aérea TAM, proprietária do terreno onde ocorreu o acidente, fez a doação do lote para a Prefeitura que estava interessada na construção de uma praça. Segundo a Prefeitura Municipal de São Paulo (2012), a criação da praça tratava-se de uma iniciativa da Secretaria 
Municipal de Desenvolvimento Urbano. E a Prefeitura de São Paulo assumiu a responsabilidade de construir um Memorial para homenagear às 199 vítimas do acidente. A Prefeitura investiu para a construção o valor de $R \$ 3,6$ milhões. A inauguração do espaço de $8.318 \mathrm{~m}^{2}$ foi em 17 de julho de 2012 e recebeu o nome de Praça Memorial 17 de Julho.

Apesar da referida Praça Memorial ter sido construída há 5 anos, poucas pessoas sabem da sua existência, sendo escassos os dados na literatura a respeito do espaço. Diante desse contexto, e levando em consideração a importância das praças e espaços públicos para o bemestar da população, a presente pesquisa teve como objetivo geral analisar a Praça Memorial 17 de Julho, identificando a infraestrutura que a compõe bem como apontar quais as dificuldades na gestão do espaço.

\section{REFERENCIAL TEÓRICO}

Os conceitos contemporâneos da paisagem, partem diretamente do princípio Homem e Natureza, assim, são poucas as paisagens que não tem, nos dias atuais, a intervenção do ser humano (CONSTANTINO; BIERNATH; MATTOS, 2016). O contato mais próximo, do homem com a natureza em metrópoles, ocorre por meio de pequenas florestas urbanas, como as que estão presentes em parques e praças. Esses espaços verdes tentam suprir a necessidade do ser humano em estar próximo a ambientes naturais.

Os espaços verdes urbanos podem ser públicos ou privados e compreende principalmente solo permeável e prevalência de grupos arbóreos ou vegetação ecológica conservacionista, proporcionando ou não atividades de recreação (MYERS, 1975; FRANCIS et al., 2012 apud BENCHIMOL et al., 2017). As pessoas, no entanto, se interessam em passar mais tempo em ambientes naturais, quando o mesmo oferece alguma atividade voltada para o meio ambiente e quando abrigam uma vasta biodiversidade (CARRUS et al., 2015).

A beleza cênica acaba atraindo a população, sendo um grande fator considerado no desenvolvimento de projetos de espaços urbanos. Para a implementação do paisagismo, neste contexto, o principal fator de decisão é a estética, ignorando muitas vezes questões ambientais (HAYDEN et al., 2015).

Um estudo desenvolvido em Chicago - Estados Unidos - apontou que, para espaços ao ar livre, as pessoas preferem atributos que proporcionem mais interação social e comunicação, que ofereçam oportunidades de trabalhos comunitários e ações que visam a conservação do meio ambiente, além de espaços rodeados de verde. Os próprios participantes da pesquisa indicaram que jardins, hortas comunitárias, bancos e espaços para piqueniques, bem como diversas árvores podem atender as preferências citadas (HADAVI; KAPLAN; HUNTER, 2015). De acordo com alguns gestores de praças, espaços públicos desprovidos de vegetação tem como principal função desempenhar um papel social (BENCHIMOL et al., 2017).

Muitos espaços públicos não atendem às expectativas das pessoas, tão pouco propiciam bemestar para os frequentadores, uma vez que os projetos não levam em consideração a percepção da população do entorno. Contudo, estudos sobre praças e parques devem receber maior atenção dos gestores, visto que fornecem informações relevantes que os auxiliam nas tomadas de decisões.

Em relação a gestão, a mesma falta de integração entre a administração de praças e parques, 


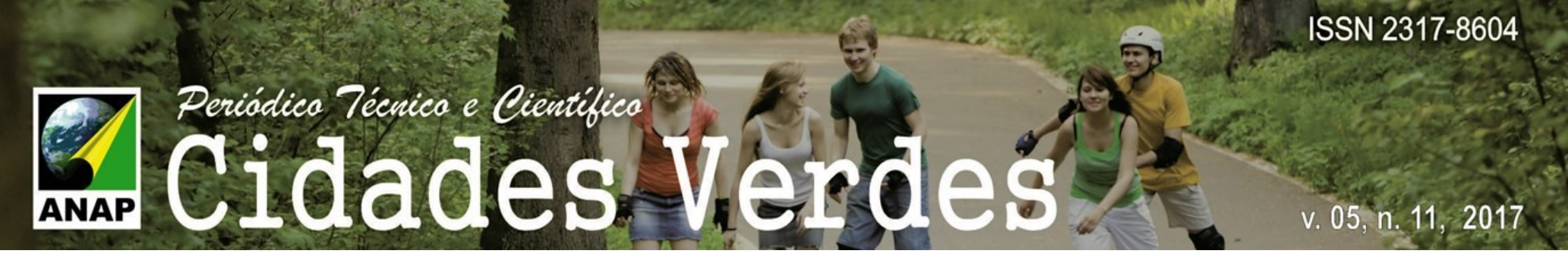

ocorre com a administração de praças e memoriais. O Departamento de Áreas Verdes das prefeituras regionais são responsáveis pelas praças, enquanto que a Secretária da Cultura é responsável pelos Memoriais.

O termo "Memorial" ainda é de difícil compreensão. Mesmo havendo diversas edificações denominadas de Memorial, a definição do termo ainda é muito vaga. Segundo o historiador Jorge Barcellos (1999), para o senso comum, museu e memorial são a mesma coisa. Entretanto, apesar de ambos se remeterem à memórias, o ICOM - International Council of Museums - o qual instituiu o comitê internacional de memoriais, aponta que o memorial tratase de um espaço para memórias mais particulares, podendo ser um memorial coletivo como o Memorial do Holocausto (Berlim - Alemanha) abordando o tema da Segunda Guerra Mundial, e remetendo-se a mais de uma pessoa, ou um memorial individualizado como o Memorial JK (Brasília - Brasil), homenageando Juscelino Kubitschek. Contudo, um memorial tem por objetivo ser um espaço de memória que homenageia algum acontecimento ou alguém e conservar um local relacionado a essa homenagem (COSTA, 2015).

\section{METODOLOGIA}

\section{1 Área de estudo}

A área de estudo da presente pesquisa foi a Praça Memorial 17 de Julho, localizada na Rua Baronesa de Bela Vista, 203 - Vila Congonhas, zona Sul de São Paulo, CEP 04074-040. As coordenadas geográficas do local é $23^{\circ} 37^{\prime} 10.67^{\prime \prime}$ latitude Sul e $46^{\circ} 39^{\prime} 43.41^{\prime \prime}$ longitude Oeste. Esta praça foi criada por meio da intervenção da Prefeitura de São Paulo, após cinco anos do acidente aéreo, envolvendo uma aeronave Airbus A320, a qual levou a morte de 199 pessoas. A inauguração do espaço de $8.318 \mathrm{~m}^{2}$ ocorreu em 17 de julho de 2012. 
para alimentação, que acabam influenciando o tempo de permanência das pessoas no local. É importante que seja avaliada a viabilidade da instalação desses itens, que tem por objetivo de fornecer recursos para estadias mais longas dos frequentadores.

A Praça Memorial também não apresenta espaços propícios para terceira idade, tornando-se um local menos atraente por pessoas dentro desta faixa etária. O mesmo ocorre com os praticantes de atividades físicas e esportivas, que muitas vezes deixam de visitar o espaço, uma vez que o mesmo não comporta estruturas que satisfaçam suas necessidades.

O espaço público estudado, fica localizado em uma área de difícil acesso, e a falta de pontos de ônibus e estações de trem ou metrô próximos, complica ainda mais a deslocação das pessoas. Além disso, no local não possui estacionamento, sendo inviável para pessoas que utilizam automóveis como meio de transporte, a frequentar a praça. O ponto de táxi identificado próximo ao espaço é uma alternativa para os visitadores que dependem de outros meios de transportes, nos quais, são ausentes.

Tabela 1: Infraestrutura da Praça Memorial 17 de Julho.

\begin{tabular}{|c|c|c|}
\hline \multicolumn{3}{|c|}{ Equipamentos / Estruturas Presentes } \\
\hline & Quantidade & Nota \\
\hline Bancos & 10 & 3 \\
\hline Iluminação & 78 & 3 \\
\hline Lixeiras & 3 & 1 \\
\hline Espelho dá água/chafariz & 1 & 1 \\
\hline Ponto de táxi & 1 & 3 \\
\hline Brinquedo para crianças & 7 & 0 \\
\hline Placas indicativas & 2 & 3 \\
\hline \multicolumn{3}{|c|}{ Equipamentos / Estruturas Ausentes } \\
\hline \multicolumn{3}{|l|}{ Sanitários } \\
\hline \multicolumn{3}{|l|}{ Telefone Público } \\
\hline \multicolumn{3}{|l|}{ Bebedouros } \\
\hline \multicolumn{3}{|l|}{ Caminhos } \\
\hline \multicolumn{3}{|l|}{ Palco/coreto } \\
\hline \multicolumn{3}{|l|}{ Obra de arte } \\
\hline \multicolumn{3}{|l|}{ Estacionamento } \\
\hline \multicolumn{3}{|l|}{ Ponto de ônibus } \\
\hline \multicolumn{3}{|l|}{ Quadra esportiva } \\
\hline \multicolumn{3}{|c|}{ Equipamentos para práticas de exercícios físicos } \\
\hline \multicolumn{3}{|c|}{ Equipamentos para terceira idade } \\
\hline \multicolumn{3}{|l|}{ Banca de revista } \\
\hline \multicolumn{3}{|c|}{ Quiosque de alimentação ou similar } \\
\hline \multicolumn{3}{|l|}{ Edificação institucional } \\
\hline Templo religioso & & \\
\hline
\end{tabular}

No entanto, a análise qualitativa indica que a maior parte dos equipamentos presentes, se encontram em bom estado de conservação e localização, exceto pelos brinquedos para as crianças, que foi classificado como péssimo por oferecer riscos de acidentes, as lixeiras à qual foi atribuído uma nota ruim, e o espelho d'água de mais de 20 mil litros, que também foi classificado como ruim, devido aos vários problemas que surgiram, inclusive pela questão da 


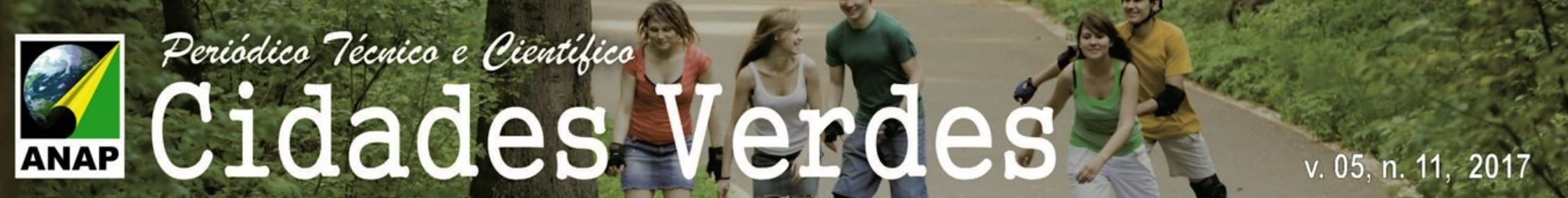

água parada, levando risco para os frequentadores e moradores do entorno da praça.

O espelho d'água, vem apresentado vazamento, e ainda não foi possível identificar a fonte do problema. O acúmulo de água parada dentro do espelho d'água pode ser locais para o desenvolvimento de larvas de mosquitos transmissores de doenças, necessitando uma melhor atenção (Figura 2).

Figura 2: Água parada e suja no espelho d'água

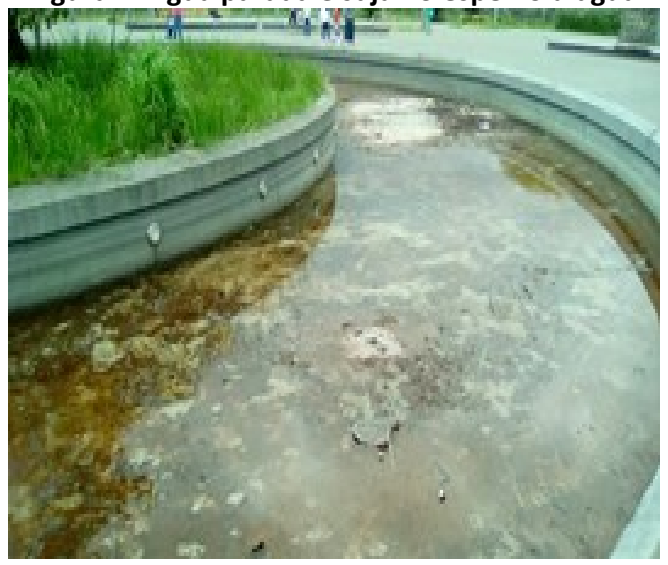

Fonte: AUTORES, 2017.

Os brinquedos infantis presentes na praça são avaliados pelo gestor como perigosos, o formato ovalado de alguns pode machucar as crianças, por esse motivo tiveram que ser soldados no piso para não terem movimentos (Figura 3). 


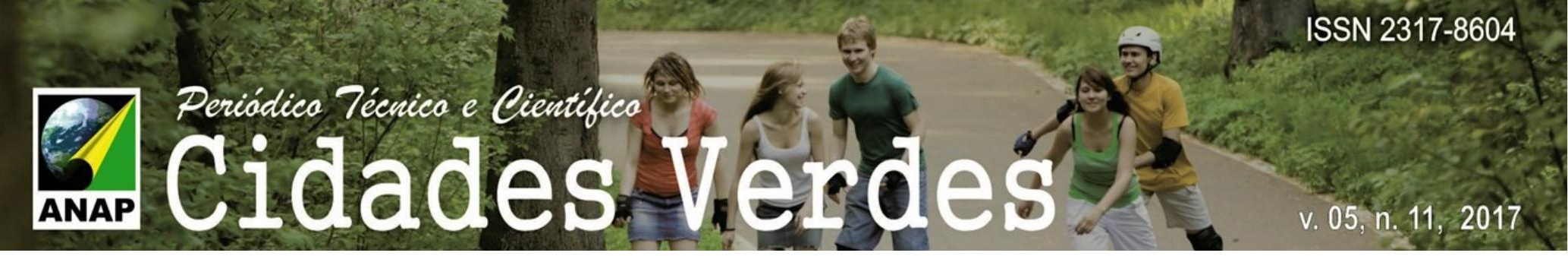

Figura 3: Brinquedos Infantis. Imagem C e D destacam os brinquedos ovalados.
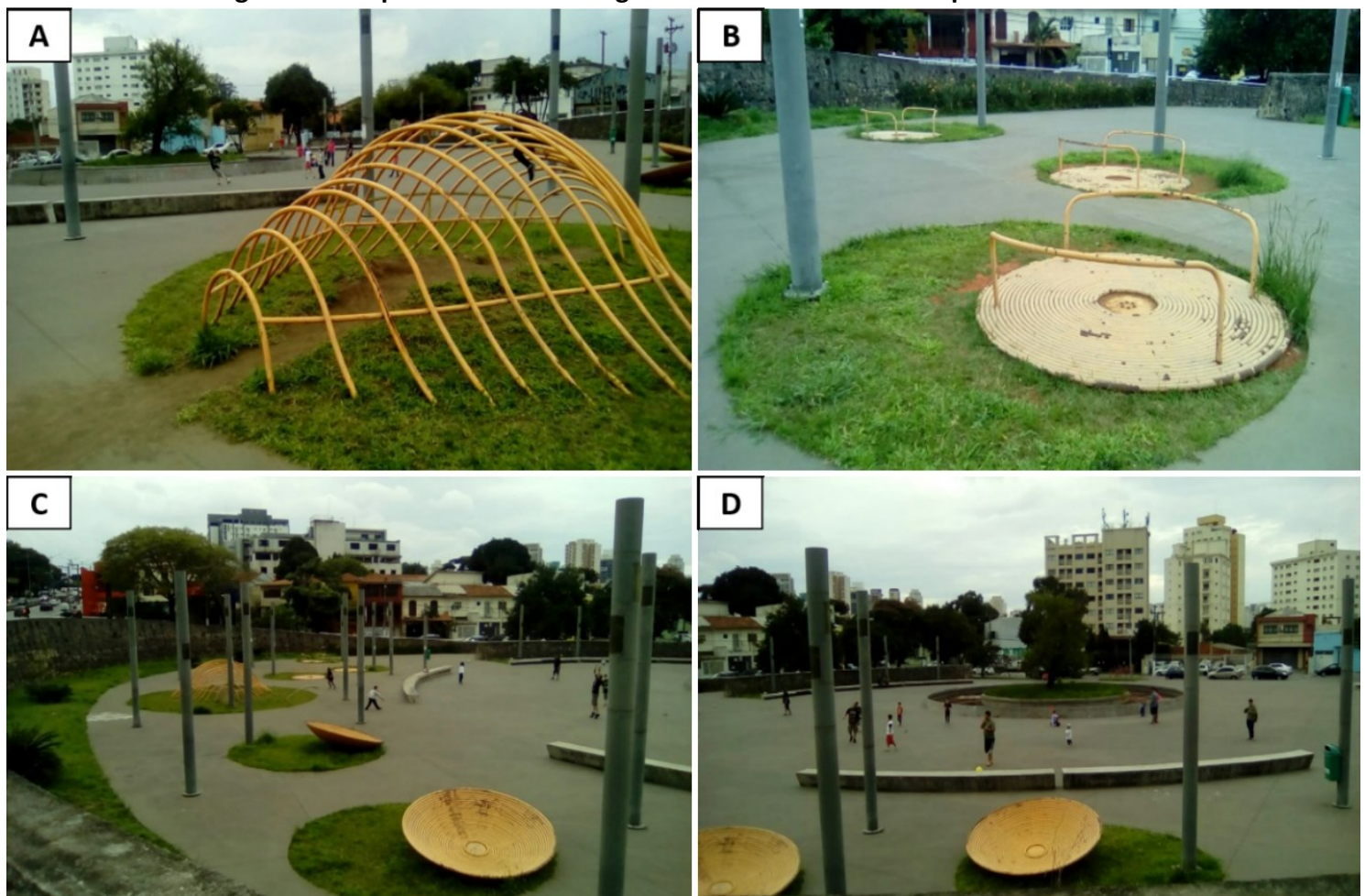

Fonte: AUTORES, 2017

De acordo com o gestor responsável, o espaço público foi planejado para ser visto a noite. Foram instaladas 199 lâmpadas de LED no chão ao redor do espaço e nas paredes do espelho d'água, que significam cada vítima que perdeu a vida no acidente aéreo do dia 17 de julho de 2007. Como homenagem, os nomes das vítimas também foram escritos com tinta no chão, porém com o tempo muitos já se apagaram.

Frequentemente a Praça Memorial, apresenta problemas de roubos de fiação elétrica, bombas d'águas e até mesmo as lâmpadas de Led. As lâmpadas das torres (postes) são raras, portanto quando queimam ou são retiradas é muito difícil conseguir verba para a reposição (Figura 4).

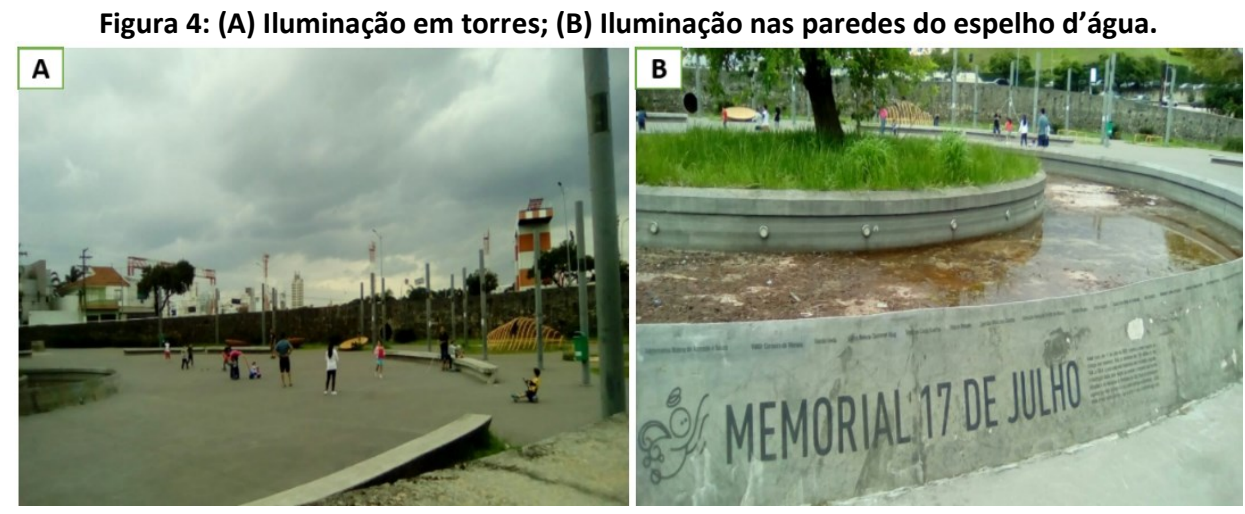

Fonte: AUTORES, 2017.

A única árvore presente no local foi uma amoreira, mantida no projeto de criação do espaço 


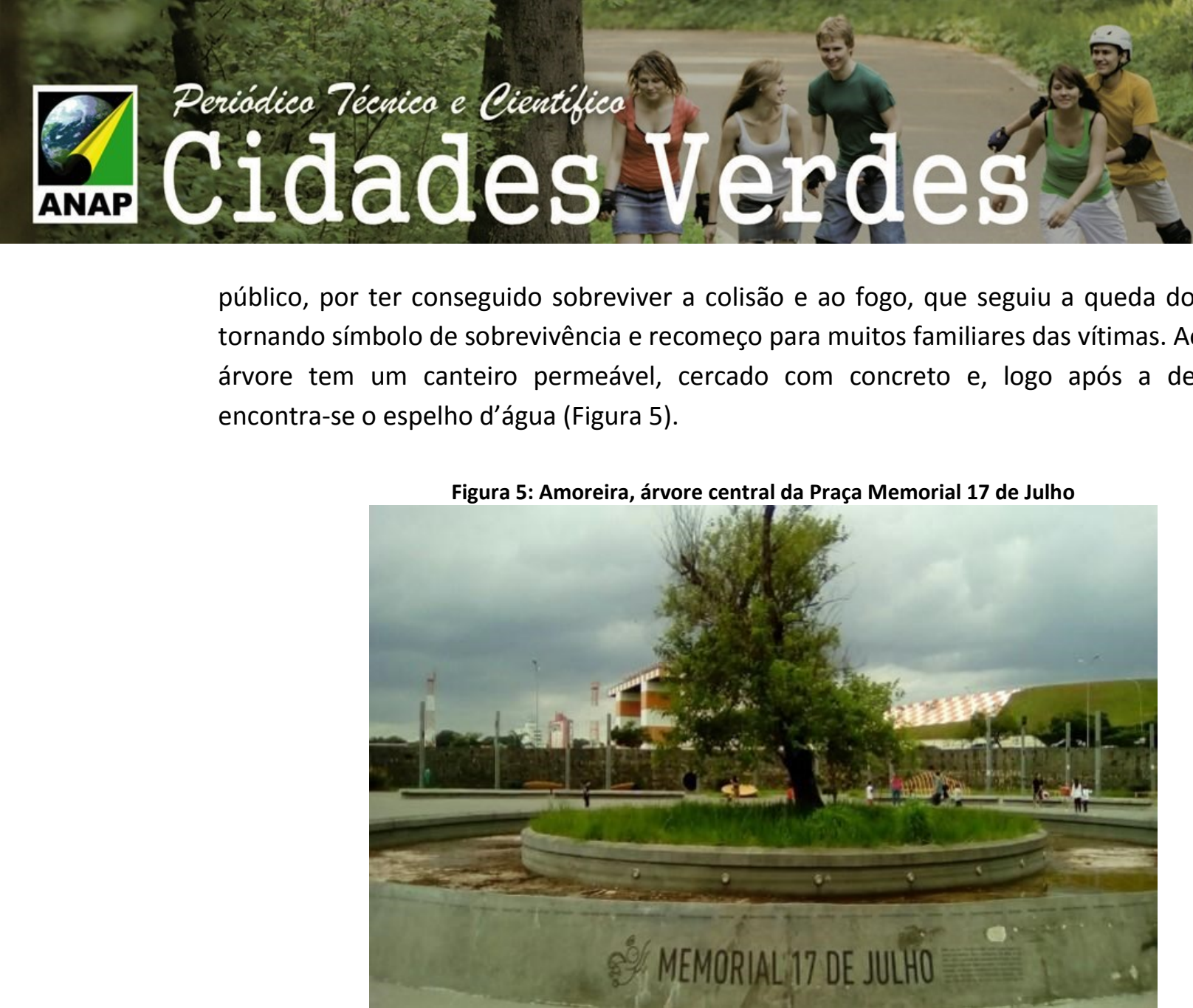

público, por ter conseguido sobreviver a colisão e ao fogo, que seguiu a queda do avião, se tornando símbolo de sobrevivência e recomeço para muitos familiares das vítimas. Ao redor da árvore tem um canteiro permeável, cercado com concreto e, logo após a delimitação, encontra-se o espelho d'água (Figura 5).

Fonte: AUTORES, 2017.

De acordo com o gestor da Praça Memorial, o projeto original elaborado pelo arquiteto chegou a prever a presença de mais vegetação e ações comunitárias, voltadas principalmente para as famílias menos favorecida em torno do aeroporto, porém, nenhuma árvore foi plantada, e nenhum projeto social foi desenvolvido, transformando num espaço seco e sem vida.

A AFAVITAM - Associação de Familiares e Amigos das Vítimas do acidente aéreo da TAM - não aprovaram o projeto realizado e asseguram que foi uma decisão unilateral da prefeitura, não havendo participação da associação em nenhum momento.

O gestor responsável pelo espaço disse ter entrado em contato com o arquiteto do projeto para propor algumas sugestões de mudanças, visando solucionar os problemas, como a substituição do espelho d'água por jardins, gravar o nome das vítimas em alto ou baixo relevo, trocar as 199 lâmpadas Led que homenageiam as vítimas por cerejeiras, porém nada mudou.

A manutenção da Praça Memorial 17 de Julho, hoje está voltada especificamente para manter a grama cortada e o espaço limpo e varrido. O gestor, por ser da prefeitura regional, afirma que suas ações são limitadas devido ao local, ser também um Memorial e não só uma praça, assim muitas decisões reportam-se à Secretaria de Cultura, e ao arquiteto responsável pelo projeto, que aparenta não ter interesse em executar melhorias no espaço, uma vez que não acatou nenhuma sugestão e tão pouco autorizou intervenções.

A prefeitura, recebeu a informação de que a LATAM tem interesse em adotar a Praça Memorial, processo esse firmado em um termo de cooperação público-privado. O que seria um excelente acontecimento, pois assim, uma instituição privada direcionaria uma verba para 
cobrir os gastos, com a manutenção e ações de conservação e interação social do espaço.

O termo de compromisso com instituições privadas podem ser novas soluções para espaços públicos que sofrem com a escassez de recursos do governo. A adoção da Praça Memorial por uma entidade privada, possibilita a revitalização do espaço, onde, um novo projeto poderia ser desenvolvido integrando o arquiteto do projeto original, o governo, a AFAVITAM, e todos que demonstrem interesse.

Pensando nessas possibilidades, a praça seria reintegrada, passando a obter mais áreas verdes, por meio de plantios mistos da vegetação, podendo incluir projetos sociais e comunitários, como era de interesse inicialmente. Além de tudo, seriam oportunidades de solucionar problemas, como os levantados nesse estudo de caso.

\section{CONCLUSÃO}

A análise quanti-qualitativa realizada permite chegar à conclusão de que há um déficit na infraestrutura na Praça Memorial 17 de Julho. Muitos equipamentos essenciais para os frequentadores de um espaço público são ausentes. Devido à falta de atividades educacionais, culturais e comunitárias, o espaço acaba tendo, pouca contribuição para a comunicação e desenvolvimento social, sendo assim, a quantidade de visitantes e o tempo de permanência dos mesmos no local, tendem a ser reduzidos.

O espaço público em questão, também deixa a desejar quando se trata de áreas verdes. A única árvore no local não é suficiente para proporcionar benefícios ecológicos, como amenização da temperatura e redução da poluição sonora e atmosférica, havendo a necessidade de mais plantios e áreas permeáveis.

A falta de conscientização de algumas pessoas, contribui para deterioração do local, uma vez que muitos materiais são retirados do lugar. Os problemas levantados, destinam-se a permanecer da mesma forma, visto que, todas as tentativas da gestão em prol de mudanças não obtiveram resultados. Atualmente a manutenção da Praça Memorial limita-se as funções básicas tentando mantê-la ao mínimo limpa, deixando muitos itens pendentes.

A maior dificuldade encontrada para a gestão do espaço é justamente a falta de integração entre o responsável por parte da praça e o responsável por parte do Memorial. A prefeitura regional de Santo Amaro por meio do Departamento de Áreas Verdes foi quem sempre geriu a Praça Memorial 17 de Julho, no entanto, devido ao espaço ser praça e memorial ao mesmo tempo, sempre há limitações e burocracia nas tomadas de decisões. 


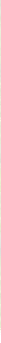

\section{REFERÊNCIAS BIBLIOGRÁFICAS}

BARCELLOS, Jorge. O Memorial como instituição no Sistema de Museus. In: Fórum Estadual de Museus, Porto Alegre, 1999.

BENCHIMOL, Juliana Furlaneto et al. Decentralized management of public squares in the city of São Paulo, Brazil: Implications for urban green spaces. Land Use Policy, v. 63, p. 418-427, 2017.

BENCHIMOL, Juliana Furlaneto; LAMANO-FERREIRA, Ana Paula do Nascimento . Distribuição de Praças Públicas na Cidade de São Paulo, SP. In: Sandra Medina Benini; Jeane Aparecida Rombi de Godoy Rosin (Org.). Estudos Urbanos: uma abordagem interdisciplinar da cidade contemporânea. 1ed.Tupã: ANAP, 2015, v. , p. 291-306.

BRASIL. Constituição da República Federativa do Brasil de 1988 Disponível em:<http://www.planalto.gov.br/ccivil_03/constituicao/constituicaocompilado.htm>, acesso em: 09 de junho de 2017.

CARRUS, Giuseppe et al. Go greener, feel better? The positive effects of biodiversity on the well-being of individuals visiting urban and peri-urban green areas. Landscape and Urban Planning, v. 134, p. 221-228, 2015.

CENIPA, Centro de Investigação e Prevenção de Acidentes Aeronáuticos. Relatório Final A - № 67/CENIPA/2009. Disponível em:<http://www2.anac.gov.br/arquivos/RF3054.pdf>, acesso em: 30 de março de 2017.

CONSTANTINO, Norma Regina Truppel; BIERNATH, Karla Garcia; MATTOS, Karina Andrade. Espaços Livres de Uso Público na Cidade Contemporânea. 1. ed. Tupã: ANAP, 2016.

COSTA, Nêemias Gonçalves. Lugares de preservação da memória: Para quê e para quem? Um estudo de caso sobre o público do memorial do Instituto Federal de Santa Catarina-Câmpus Florianópolis. Trabalho de Conclusão do Curso de Museologia. Florianópolis: Universidade Federal de Santa Catarina, 2015.

DORIGO, Tania Aparecida; LAMANO-FERREIRA, Ana Paula do Nascimento. Contribuições da Percepção Ambiental de Frequentadores sobre Praças e Parques no Brasil (2009-2013): Revisão Bibliográfica. Revista de Gestao Ambiental e Sustentabilidade, v. 4, p. 31-45, 2015.

FRANCIS, Jacinta et al. Creating sense of community: The role of public space. Journal of Environmental Psychology, v. 32, n. 4, p. 401-409, 2012 apud BENCHIMOL, Juliana Furlaneto et al. Decentralized management of public squares in the city of São Paulo, Brazil: Implications for urban green spaces. Land Use Policy, v. 63, p. 418-427, 2017.

HADAVI, Sara; KAPLAN, Rachel; HUNTER, Mary Carol R. Environmental affordances: A practical approach for design of nearby outdoor settings in urban residential areas. Landscape and urban planning, v. 134, p. 19-32, 2015.

HAYDEN, Lillian et al. Residential landscape aesthetics and water conservation best management practices: Homeowner perceptions and preferences. Landscape and Urban Planning, v. 144, p. 1-9, 2015.

LOBODA, Carlos Roberto; DE ANGELIS, Bruno Luiz Domingues. Áreas verdes públicas urbanas: conceitos, usos e funções. Ambiência, v. 1, n. 1, p. 125-139, 2009.

MYERS, Marilyn. Decision making in allocating metropolitan open space: state of the art. Transactions of the Kansas Academy of Science, v. 78, n. 3/4, p. 149-153, 1975 apud BENCHIMOL, Juliana Furlaneto et al. Decentralized management of public squares in the city of São Paulo, Brazil: Implications for urban green spaces. Land Use Policy, v. 63, p. 418-427, 2017.

Prefeitura Municipal de São Paulo. Prefeitura inaugura Praça Memorial 17 de Julho. Disponível em: $<w w w . p r e f e i t u r a . s p . g o v . b r / c i d a d e / s e c r e t a r i a s / o b r a s / s p \_o b r a s / n o t i c i a s / ? p=43425>$, acesso em 23 de abril de 2017. 


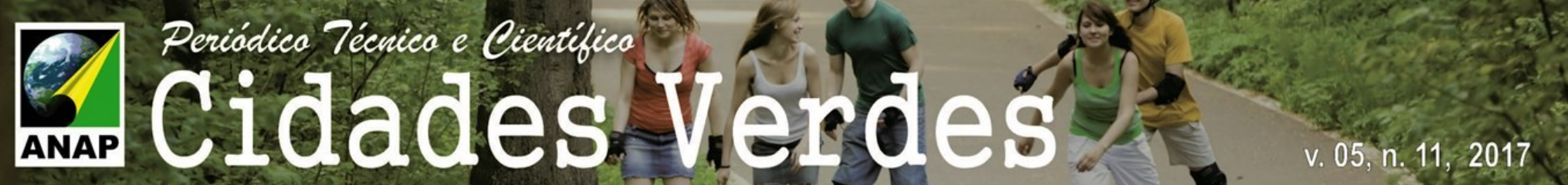

SCHIPPERIJN, Jasper et al. Factors influencing the use of green space: Results from a Danish national representative survey. Landscape and urban planning, v. 95, n. 3, p. 130-137, 2010. 